Lexis Vol. XLI (2) 2017: 455-468

\title{
El Quijote de Coseriu
}

Jorge Wiesse Rebagliati

Universidad del Pacífico

\section{RESUMEN}

En su amplia obra lingüística, Eugenio Coseriu (Mihaileni, 1921 - Tübingen, 2002), acude varias veces a la literatura para ejemplificar conceptos lingüísticos teóricos e incluso para modelarlos. Como ocurre con varios estudiosos del siglo XX (José Ortega y Gasset o Mijaíl Bajtín, por ejemplo), el Quijote es, para Coseriu, incitación para formular reflexiones que no se aplican exclusivamente a él, como sí lo hacen otras obras relevantes del cervantismo del siglo XX, señaladamente los trabajos de Stephen Gilman y Edward C. Riley. El presente artículo busca rastrear las referencias al Quijote y a Cervantes en la obra de Coseriu y, sobre todo, presentar y discutir la corrección hecha por Coseriu al importante trabajo de Leo Spitzer "Perspectivismo lingüístico en el Quijote”.

Palabras clave: Cervantes, Leo Spitzer, Don Quijote de la Mancha, Eugenio Coseriu

\section{AbSTRACT}

In his extensive linguistic work, Eugenio Coseriu (Mihaileni, 1921 Tübingen, 2002), uses literature several times to exemplify theoretical linguistic concepts and even to model them. As is the case with several 20th century scholars (José Ortega y Gasset or Mijaíl Bajtín), Don Quixote is, for Coseriu, a touchstone to formulate reflections that do not 
apply exclusively to it, as other relevant works of 20th century's Cervantism, such as Stephen Gilman's or and Edward C. Riley's, do. This article seeks to trace the references of Don Quixote and Cervantes in Coseriu's work and, above all, to present and discuss the correction made by Coseriu to Leo Spitzer's "Perspectivismo lingüístico en el Quijote". Keywords: Cervantes, Leo Spitzer, Don Quijote de la Mancha, Eugenio Coseriu

De Unamuno ${ }^{1}$ a Borges ${ }^{2}$ y de Picasso a Dalí, podría afirmarse sin hipérbole que el Quijote activó una buena cantidad de reflexiones y creaciones de alto nivel a lo largo del siglo XX. Dos conceptos clave para comprender la filosofía de Ortega y Gasset - la perspectiva y la circunstancia- se gestaron en su ya centenario clásico: Meditaciones del Quijote ([1914] 2014).

Si nos concentramos propiamente en la teoría de la literatura, resulta difícil pasar por alto planteamientos tan importantes para la teoría de la novela en general como El "Quijote" y la poética de la novela de Félix Martínez Bonati (2004) o las reflexiones de Mijaíl Bajtín (1991) sobre los sonetos iniciales de la primera parte del Quijote para la consideración del género “soneto burlesco", títulos que se distinguen de obras tan importantes, aunque más cerradamente cervantinas, como La novela según Cervantes de Stephen Gilman (1993) y la Teoría de la novela en Cervantes de Edward C. Riley (1966).

A lo largo de su extensa obra, autodenominada por su creador "lingüística integral” (en la que se incluye a la lingüística del texto como hermenéutica del sentido, cuyos objetos privilegiados son las obras de arte literarias), Eugenio Coseriu (Mijaileni, 1921-Tubinga, 2002) acude al Quijote de Cervantes para ejemplificar o ilustrar ideas puntuales. Así, al referirse a la condición — digamos— “ontológica” de la obra literaria, sostiene que la obra de arte literaria,

\footnotetext{
Véase Vida de Don Quijote y Sancho de Unamuno (2004).

Véase Cervantes y el Quijote de Borges (2005).
} 
propiamente, no informa, sino crea, no "dice", sino "hace". A propósito de ello, como afirma el maestro rumano, Cervantes no “[...] 'cuenta' lo que le pasó a Don Quijote con los molinos de viento, sino que 'hace' que Don Quijote se enfrente a los molinos de viento" (Coseriu 2006b: 94-95); en síntesis, “en la literatura se inventa la realidad misma y el discurso coincide con esa creación de la realidad" (Coseriu 2006b: 95).

Otro de los planteamientos coserianos relativos a las creaciones literarias ejemplificados con la obra de Cervantes (y también con la de Kafka) es el de lo secundario del idioma para la configuración de estos objetos artísticos. ${ }^{3}$ En efecto, Coseriu sostiene lo siguiente:

La lengua en que ambos [Cervantes y Kafka] han escrito sus obras solo contribuye al sentido mediante una característica universal: la de que en toda lengua se puede hacer referencia a lo extralingüístico. (Coseriu 2007: 296)

Y ofrece como prueba de ello la especial facilidad con que las obras de Cervantes y de Kafka se trasponen a otros medios artísticos (la pintura, el cine, etc.). Sostiene Coseriu:

El Quijote y la obra entera de Kafka [...] pueden traducirse con especial facilidad porque los hechos lingüísticos importantes para la construcción del sentido de estas obras [...] no están vinculados a ninguna obra en particular; es más, en tanto que portadores del sentido, tienen una relevancia tan limitada que el sentido de estos textos puede traducirse en medios expresivos completamente distintos. (2007: 297)

Paradójicamente, estas consideraciones no anulan el valor que Coseriu puede asignarle al estilo de Cervantes, que puede identificarse - como el de Dante o como el de Shakespeare- con la ejecución más lograda de las posibilidades sistemáticas de la lengua

3 Para una crítica de este aspecto del razonamiento coseriano, véase Wiesse Rebagliati (2012), "Sentido y ámbito. Una apostilla a la teoría de la literatura de Eugenio Coseriu”, pp. 343 ss. y también Wiesse Rebagliati (2017), “¿Una poética de la designación? Posibilidades y límites de una distinción coseriana”, pp. 42 ss. 
en que cada uno de ellos escribió. Dentro de la concepción coseriana, tendría sentido referirse al español como "la lengua de Cervantes" o, más propiamente, “el idioma de Cervantes” (como al italiano "el idioma de Dante” y al inglés “el idioma de Shakespeare”), pues la norma lingüística individual de Cervantes —su estilo- coincide con la ejecución más rica de las posibilidades del sistema lingüístico del español (Coseriu 2007: 1970, n.75).

Coseriu se ha ocupado incluso de la recepción del Quijote o de esa curiosa apropiación de la novela realizada por Pierre Menard, el personaje creado por Jorge Luis Borges. En efecto, recurre al cuento de Borges para explicar la distinción designación-significadosentido (Coseriu 1992: 96), "una de tantas tricotomías coserianas”, como diría Johannes Kabatek (Coseriu 2006a: 9). Según Coseriu, la interpretación de la obra de arte coincide con la captación - y la ulterior descripción, en el caso del crítico- de su sentido. Para ello, se apoya en la designación y el significado, que constituyen la parte “significante” del signo estético (el "significado" de este signo es el sentido). En opinión de Coseriu, en el cuento de Borges, Menard reproduce exactamente la designación y el significado del Quijote, pero no su sentido:

Es decir, que el hombre [Pierre Menard] conoce exactamente todo lo dicho, pero no muestra ninguna comprensión por el sentido, y de ese modo se queda en la reordenación exacta de los significantes [como suma de los significados y las designaciones, observación de Óscar Loureda Lamas], pero no del sentido. (Coseriu 2007: 155)

Creemos que a Coseriu se le escapa, en este punto particular, la sutileza borgiana. Sería demasiado simple que Menard solo reprodujera el texto de Cervantes: el Quijote de Menard ya no es el de Cervantes. Escrito por un simbolista francés a principios del siglo XX, el Quijote debe ser interpretado de otra manera. En términos coserianos, para descubrir el sentido de este texto, debe considerarse un aspecto de la designación: el entorno y, concretamente, el tipo específico de entorno denominado por el estudioso rumano “contexto extraverbal cultural” (Coseriu 1967: 317). El mismo 
Coseriu describe una operación semejante a partir de un análisis propuesto por Benedetto Croce: una transformación del texto, esta vez de un soneto de Tansillo por Giordano Bruno, es interpretada por el profesor de Tübingen como un caso de aplicación de otro tipo de entorno, el “contexto verbal mediato" (Coseriu 2007: 242). Al final, en la línea de George Steiner, se trata de la paradoja de la traducción: el texto es "el mismo" y, a la vez, "otro". ${ }^{4}$

El tema cervantino al que Coseriu dedicó más atención es el del sentido del Quijote. ${ }^{5}$ Para ello, discute una propuesta de Leo Spitzer, el famoso investigador austríaco. Es bien conocido el artículo "Perspectivismo lingüístico en el Quijote” de Spitzer (1973b), aunque quizás no tanto como texto teórico o como aplicación puntual de conceptos teóricos. Probablemente, se conozca poco también el juicio de Eugenio Coseriu sobre este estudio spitzeriano. Como una contribución a la historia de la teoría de la literatura del siglo XX, creo pertinente exponer los términos elementales de una polémica mínima, casi secreta, pero importante y relevante para la constitución de una de las teorías de la literatura más originales $-\mathrm{y}$, a la vez, más tradicionales- de la segunda mitad del siglo XX: la basada en la lingüística del texto entendida como hermenéutica del sentido de Eugenio Coseriu.

Comenzaré reseñando brevemente las ideas teóricas de Leo Spitzer. En su famoso artículo "Lingüística e Historia Literaria”,

4 Véase Steiner (1992), pp. 73-76 y Vinatea (2010). Steiner afirma que "Pierre Menard, autor del Quijote" es "the most acute, the most concentrated commentary anyone has offered on the business of translation" (1992: 73). A su vez, Vinatea sostiene que "la posición que adopta Menard se anticipa casi tres décadas a los postulados de la estética de la recepción [de H. R. Jauss y otros]” (2010: 163).

5 El origen más remoto de la reflexión coseriana parece ser una conferencia de la época de Montevideo revisada y presentada en Lima; apunta Óscar Loureda: "Según los datos recogidos por José Polo en el Archivo Coseriu, la mencionada disertación bajo el título "El lenguaje de Cervantes", fue impartida el 25 de junio de 1955 en la Casa de España de Montevideo, dentro del ciclo de conferencias 350 aniversario de la publicación de El Quijote, en buena parte coincide con una segunda titulada "Cervantes y el lenguaje”, impartida el 7 de noviembre de 1997 en la Facultad de Letras y Ciencias Humanas de la Pontificia Universidad Católica del Perú (Lima) dentro del coloquio Miguel de Cervantes Saavedra: 450 años (Coseriu 2007: 28, n. 241). 
Spitzer (1973a) sostiene que su método se basa en la intuición y que se aplica tanto a la lingüística (por ejemplo, al descubrimiento de una etimología) como a la literatura (por ejemplo, a la interpretación de un texto literario). Siguiendo a Schleiermacher y a Dilthey, Spitzer sostiene que la operación fundamental en las humanidades es el Zirkel im Verstehen o movimiento circular de entender (Spitzer 1973a: 39). En filología, el conocimiento no se alcanza solamente por la progresión gradual de uno a otro detalle, sino por la anticipación o adivinación del todo, porque "el detalle solo puede comprenderse en función del todo y cualquier explicación particular presupone la comprensión del conjunto” (Schleiermacher) (Spitzer 1973a: 40). Spitzer aplica un método de vaivén de algunos detalles externos al centro interno, y a la inversa, del centro a otras series de detalles (1973a: 41). Según él, esto no es sino la aplicación al conocimiento lingüístico y textual del "círculo filológico" (1973a: 40). En términos de una explicación textual, el centro no es otra cosa que el étymon o sentido.

En su estudio “Perspectivismo lingüístico en el Quijote”, Spitzer va, precisamente, de la periferia al centro y viceversa, para descubrir el étymon. En sus palabras: "Cualquier aspecto periférico, si seguimos su pista atentamente hasta el centro, nos permitirá echar una mirada al interior del conjunto artístico, cuya unidad, de este modo, habrá sido respetada" (1973b: 163).

De manera concreta, Spitzer observa que en el Quijote se verifica una inestabilidad de los nombres (1973b: 163). A pesar de la obsesión de Don Quijote por la corrección lingüística, se verifican permanentemente polionomasias y polietimologías — estas últimas, como era usual en el Medioevo, generadas por descomposición y no, como lo haría un lingüista actual, por derivación. Así, la palabra inglesa dismal 'aciago, triste' se explicaba como "dies mali” (= día aciago), en lugar de derivarlo de "disme" (= diezmo)—. Descomponer el nombre de la Condesa Trifaldi en “tres faldas” es una etimología de este tipo.

Para Spitzer, la polionomasia se presenta a veces como un excurso de geografía lingüística. Así, en I, 2, el narrador se refiere a 
"un pescado que en Castilla llámase abadejo y en Andalucía bacallao y en otras partes curadillo y en otras truchuela" (Cervantes 1998: 53). Sin embargo, donde más se aprecia este procedimiento lingüístico es en la inestabilidad de los nombres propios, señalada en el del protagonista. Sostiene Spitzer:

Cualquier lector del Quijote queda sorprendido por la inestabilidad de los nombres de los principales personajes de la novela. En el capítulo primero nos dice Cervantes que el protagonista era llamado por "los autores de la verdadera historia" alternativamente Quijada, Quesada o Quijana (siendo esta última, a juicio de Cervantes, la "conjetura" más verosímil). De esta colección [de nombres] eligió el "ingenioso hidalgo", antes de dar principio a su profesión de caballero andante, el nombre que había de llevar a lo largo de todo el libro: Quijote. Cuando al final queda curado de su fiebre de quijotismo y abomina de Amadís de Gaula, así como de las demás novelas de caballerías, recobra su antiguo nombre prosaico y sin pretensiones (II, 74): “ya no soy don Quijote de la Mancha, sino Alonso Quijano, a quien mis buenas costumbres me dieron renombre de Bueno" (Cervantes 1998: 1217) y la escena final de su muerte y resignación cristianas - sigue Spitzer- parece enmarcada en una atmósfera de rebautismo, al volver al "loco" a ser "cuerdo" (tres veces, en el capítulo final, se menciona el cambio de nombre, como si quisiera el autor meternos bien en la cabeza que el viejo Adán había muerto). (1973b: 164)

Spitzer sospecha que estas polionomasias y polietimologías apuntan a un motivo psicológico de Cervantes (1973b: 161). La deliberada renuncia del autor a elegir definitivamente un nombre (o una etimología) es manifestación de su deseo de destacar los diferentes aspectos bajo los que puede aparecer a los demás el personaje en cuestión. Parece que Cervantes mirase el lenguaje desde el ángulo del perspectivismo (Spitzer 1973b: 161), ${ }^{6}$ como en efecto lo reconoció Américo Castro. Ahora, como es Cervantes quien otorga esta

\footnotetext{
6 Según Coseriu, "Leo Spitzer ve en la inseguridad de los nombres una muestra del perspectivismo lingüístico. En efecto, sigue una idea medieval según la cual el hombre no conoce la realidad de las cosas, pues solo Dios conoce las esencias y, por tanto, el verdadero nombre de las cosas" (2006c: 124).
} 
libertad y concede este perspectivismo a la narración, Spitzer afirma que es en la glorificación del artista donde hemos de ver la mayor significación histórica de la obra cumbre de la literatura española (1973b: 162).

Además de incurrir en la "falacia biográfica" (criticada desde la época del "New Criticism") de identificar autor y narrador, o de reducir el sentido de un texto a los supuestos contenidos psicológicos experimentados por su autor al crearlo, no se ve cómo de la inestabilidad de los nombres y el consecuente perspectivismo se deba derivar que la glorificación del artista constituya el sentido último del Quijote. En realidad, cualquier autor posee esta libertad narrativa.

Sin manifestarlo explícitamente, Eugenio Coseriu, en su Lingüistica del texto. Introducción a la bermenéutica del sentido (2007), observa esas inconsecuencias. Pero su crítica más abierta va por otro lado: Coseriu se percata de que a las agudas observaciones de Spitzer les falta un mejor sistema para articular el sentido (y quizás por ello se presenten las inconsecuencias mencionadas).

Coseriu trata el tema a propósito de su reflexión acerca de la condición de lingüística del texto ante litteram de la estilística "integral” de Leo Spitzer. Como sostiene el maestro rumano, Spitzer interpreta los textos en el plano del sentido (no es otra cosa la búsqueda del étymon, del "centro" a partir de la "periferia” del texto) y, por ello, está justificado ver en su estilística un prometedor avance de una lingüística del sentido (Coseriu 2007: 264). No obstante, para poder llegar a una “verdadera” lingüística del texto — sigue Coseriu- habría que ampliar la estilística de Spitzer, lo que le proporcionará una base más sistemática (2007: 264).

En la estilística de Spitzer, Coseriu echa de menos un componente que podría denominarse teoría de la articulación del sentido. Coseriu observa que por la investigación y la descripción de las lenguas, se sabe que los contenidos lingüísticos están vinculados a sus estratos correspondientes, es decir, que hay distintos contenidos específicos en los diversos niveles de estructuración idiomática. Así, por ejemplo, el significado de una oración no puede representarse 
simplemente como la suma de los significados de las palabras que en ella se combinan (2007: 264). En esta línea, concluye que habría que estudiar en profundidad los "sillares" de las unidades de sentido complejas y cómo se disponen para formar unidades de sentido de rango superior (2007: 264). Según Coseriu, las unidades, de menor a mayor, son las siguientes: de una unidad minima, aún por definir (pero que podría corresponder, según Óscar Loureda, siguiendo a Émilie Benveniste, al enunciado), al párrafo; de este al capítulo y del capitulo a la obra entera. Y aún más: a la totalidad de la obra de un autor, lo que en francés se denomina ouvre (2007: 264-265):

$$
\begin{aligned}
& \text { obra (oeuvre) } \\
& \text { “obra entera” } \\
& \text { capítulo } \\
& \text { párrafo } \\
& \text { enunciado }
\end{aligned}
$$

En opinión de Coseriu, Spitzer ocasionalmente apunta que ciertos hechos comprobados en un pasaje de un texto están en conexión con otros hechos que aparecen en lugares completamente distintos del mismo texto, pero no logra llegar hasta el final, es decir, a comentar un texto tan pormenorizadamente que pudieran reconocerse nexos más amplios. Si lo hubiese hecho, también él habría comprendido que una dimensión de sentido que aparece en el texto no coincide necesariamente con el sentido del conjunto de un texto (Coseriu 2007: 265), que es lo que ocurre con su explicación del sentido total del Quijote basada en la inestabilidad de los nombres, a la que Spitzer vincula con el perspectivismo y la posterior glorificación del artista por Cervantes.

Coseriu cree que Spitzer tiene razón al reconocer la pluralidad de los nombres del Quijote como un rasgo particularmente llamativo; y hasta cierto punto la interpreta correctamente. Lo que se cuestiona es si esa interpretación es válida para la obra en su conjunto, esto es, si constituye realmente el sentido de la novela o solamente el sentido de un componente de la novela. Coseriu sostiene que el 
tema de la "inestabilidad de los nombres" es un factor entre otros (2007: 265), que no puede comprenderse sin relación a otros y que no puede presentarse, exclusivamente (ni aunque se lo asocie al perspectivismo), como el sentido total de la novela cervantina.

Como otro componente, como otro "sillar", que ayuda a construir el sentido final del Quijote, Coseriu menciona el tema de la libertad. Una de las actividades preferidas de Don Quijote es liberar a distintos personajes, independientemente de si estos quieren ser liberados e independientemente de si se lo reconocerán o agradecerán. Don Quijote habla frecuentemente sobre la libertad. El famoso discurso a Sancho sobre esta en II, 58, no es sino el más célebre de muchos ejemplos. Para Coseriu, forma parte del tema de la libertad otra parte de la acción de la novela, una variación burlesca de la rica tradición literaria sobre la utopía y sobre la descripción del estado ideal: el gobierno de Sancho Panza sobre la ínsula Barataria (2007: 268-269).

Dentro de este contexto, la inestabilidad de los nombres no es solo una manifestación de inseguridad, sino también un momento de libertad:? somos libres para dar nombres a las cosas porque toda denominación se corresponde con una determinada visión, esto es, con un determinado modo de ver las cosas (Coseriu 2007: 269).

Concluye Coseriu, entonces, que el Quijote es un poema sobre la libertad, pues la libertad es el verdadero tema de esta novela. Sin embargo, se trata de un tema trágico porque Don Quijote solo puede luchar por la libertad cuando está loco. Como afirma Coseriu, las posibilidades de luchar por la libertad son limitadas, dado que la libertad está en inmediata conexión con la demencia del héroe, y en que este abandona la búsqueda de la libertad para sí y para los demás precisamente cuando él, definitivamente vencido, cree haber sanado: recobrada la salud, recupera, al mismo tiempo, la infinita monotonía de la vida, de la que había salido al principio, cuando

\footnotetext{
7 "Por mi parte, considero, sobre la base de lo que se encuadra en la construcción del sentido de esa gran novela, que esa inseguridad es producto de la libertad del nombrar, pues la libertad es el motivo de la novela y se presenta en cada momento [...]” (Coseriu 2006c: 124).
} 
estaba lleno de aquel "demencial” entusiasmo por la libertad que constituye su verdadera esencia. Ahora, curado, no volverá a liberar a nadie, ni luchará más por la justicia; ahora, si no se lo hubiese impedido la muerte, volvería a comer su "olla de algo más vaca que carnero, salpicón las más de las noches, duelos y quebrantos los sábados, lentejas los viernes y algún palomino de añadidura los domingos" (Coseriu 2007: 269-270). Como lo señala Coseriu en su artículo "Textos, valores, enseñanzas":

Está tan venido a menos que ve cuerda la vida absurda y cotidiana, y siente [como] locura lo que era su sabiduría. Todos los lectores perciben, al menos intuitivamente, este hecho, y no ven, en cambio, una sátira de las novelas de caballerías: intuyen que la esencia de la novela es la defensa de la libertad. (2006c:124)

El “edificio” del sentido podría quedar, según Coseriu, representado en el siguiente esquema (2007):

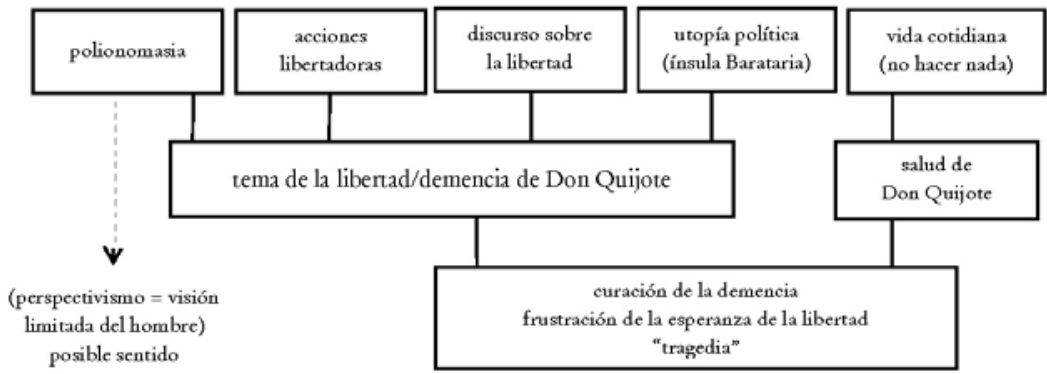

Como se ha visto, las concepciones del sentido del Quijote de Leo Spitzer y de Eugenio Coseriu, aunque distintas, se complementan.

Coseriu llega a reconocer la intuición de Spitzer y la completa dentro de un sistema de articulación de sentido más riguroso. Para llegar a él, sin embargo, Coseriu probablemente habrá tenido que recurrir al círculo filológico de Spitzer y contrastar sus observaciones parciales con su intuición de la totalidad, del conjunto. 
En mi caso, siento que para un tema como este, apenas he esbozado un conjunto de tanteos y de paráfrasis dispersas, pero que son indispensables para llegar a articular una totalidad que tenga más sentido, pues como dice Coseriu, la articulación de este se verifica preferentemente en las obras literarias, pero no solo en ellas (2007: 265), también en un artículo como este.

\section{Referencias bibliográficas}

BAjTín, Mijaíl

1989 Teoría y estética de la novela. Trads., Helena Kriúkova y Vicente Cascarra. Madrid: Taurus.

BORGES, Jorge Luis

2005 Cervantes y el Quijote. Edición compilada y realizada por Sara Luisa del Carril y Mercedes Rubio de Zocchi. Buenos Aires: Emecé.

Cervantes, Miguel de

1998 Don Quijote de La Mancha. Eds., Francisco Rico y Joaquín Forradellas. Barcelona: Instituto Cervantes-Crítica.

Coseriu, Eugenio

[1955-1956] “Determinación y entorno. Dos problemas de una lingüística 1967 del hablar". (Originalmente en Romanistisches Jabrbuch, 7, 24-54). En Teoría del lenguaje y lingüística general. Madrid: Gredos, 281-323.

1992 Competencia lingüistica. Madrid: Gredos.

2006a Lenguaje y discurso. Ed., Óscar Loureda Lamas. Navarra: EUNSA.

2006b “Información y literatura”. En Coseriu 2006a: 85-99.

2006c “Texto, valores, enseñanza”. En Coseriu 2006a: 113-126.

2007 Lingüistica del texto. Introducción a la bermenéutica del sentido. Edición, anotación y estudio previo de Óscar Loureda Lamas. Madrid: Arco/ Libros.

Gilman, Stephen

1993 La novela según Cervantes. Prólogo de Roy Harvey Pearce. México D.F.: Fondo de Cultura Económica. 
LASKIER-MarTín, Adrienne

1991 Cervantes and the Burlesque Sonnet. Berkeley-Los AngelesOxford: The University of California Press.

Martínez Bonati, Félix

2004 El "Quijote" y la poética de la novela. Santiago de Chile: Editorial Universitaria.

Ortega y Gasset, José

[1914] 2014 Meditaciones del Quijote. Edición conmemorativa del Centenario. Estudio introductorio por Javier Zamora Bonilla. Apéndice de variantes (edición crítica) por José Ramón Carriazo Ruiz. Madrid: Fundación Ortega-Marañón, Alianza Editorial, Publicaciones de la Residencia de Estudiantes.

Riley, Edward C.

1966 Teoria de la novela en Cervantes. Madrid: Taurus.

SPITZER, Leo

1973a “Lingüística e Historia Literaria”. En Lingüistica e Historia literaria. Madrid: Gredos, 7-63.

1973b "Perspectivismo lingüístico en el Quïjote". En Lingüística e Historia literaria. Madrid: Gredos, 161-225.

STEINER, George

1992 After Babel. Aspects of Language and Translation. Segunda edición. New York: Oxford University Press.

Unamuno, Miguel de

2004 Vida de Don Quijote y Sancho. Madrid: Alianza Editorial.

Vinatea, Martina

2010 "Pierre Menard, autor del Quijote: una reflexión sobre la práctica del comentario textual”. Apuntes 67. 157-169. https:// doi.org/10.21678/apuntes.67.612

Wiesse Rebagliati, Jorge

2012 "Sentido y ámbito. Una apostilla a la teoría de la literatura de Eugenio Coseriu”. En Eugenio Coseriu (1921-2002) en los comienzos del siglo XXI. Coord., Jesús Martínez del Castillo. Analecta Malacitana. Anejo LXXXVI de la Revista de la Sección de Filología de la Facultad de Filosofía y Letras. Málaga: Universidad de Málaga, 331-358. 
2013 "Función del soneto en el Quijote". Anales Cervantinos. XLV. Madrid: CSIC, 325-340. https://doi.org/10.3989/anacervantinos.2013.013

2017 “¿Una poética de la designación? Posibilidades y límites de una distinción coseriana”. En Kompetenz-Funktion-Variation. Competencia-Función-Variación. Linguistica Coseriana $V$. Eds., Gerda Hassler y Thomas Stehl. Frankfurt: Peter Lang, 39-53.

Recibido: 06/09/2017 Aceptado: 24/10/2017 